\title{
International Versus Domestic Auditing of Bank Solvency
}

Andrew Feltenstein and Roger Lagunoff 


\title{
IMF Working Paper
}

\author{
IMF Institute \\ International Versus Domestic Auditing of Bank Solvency
}

Prepared by Andrew Feltenstein and Roger Lagunoff ${ }^{1}$

September 2003

\begin{abstract}
The views expressed in this Working Paper are those of the author(s) and do not necessarily represent those of the IMF or IMF policy. Working Papers describe research in progress by the author(s) and are published to elicit comments and to further debate.
\end{abstract}

This paper examines alternative ways to prevent losses from bank insolvencies. It is widely viewed that transparency in reporting bank balance sheets is a key element in reducing such losses. It is, however, unclear just how such transparency would be achieved. Current approaches to avoiding insolvencies generally involve international enforcement mechanisms. Among these are the sovereign debt restructuring mechanism (SDRM), and, more generally, an international bankruptcy court.

We develop a model that compares two alternative institutions for bank auditing. Neither of these institutions would require as much enforcement capability as an international bankruptcy court, hence they would be easier to introduce. The first of these is a system of central bank auditing of national banks. The second type of auditing is carried out by an international agency that collects risk information on banks in all countries and then provides it to depositors. Using a game-theoretic approach, we compare the informativeness of the disclosure rule in the symmetric Perfect Bayesian equilibrium in each of the two different auditing institutions. We show that the international auditor generally performs at least as well, and sometimes better than, auditing by either central banks, which, in turn, perform better than voluntary disclosure by the banks themselves. The results do not assume any informational advantages of the international auditor, nor is the international auditor somehow less "corrupt" than the central banks. Rather, the international auditor's credibility comes from the simple fact that its incentives are not distorted by a sovereignty bias that plagues the central banks.

JEL Classification Numbers: G1, G2, M4

Keywords: Bank Insolvency, Auditing, International Auditing

Authors’ E-Mail Addresses: afeltenstein@imf.org; lagunofr@georgetown.edu; www.georgetown.edu/lagunoff/lagunoff.htm

${ }^{1}$ We thank Anne Epaulard, Stephen Morris, and seminar participants at the IMF Institute for helpful comments and suggestions. The views expressed in this paper do not necessarily reflect those of the International Monetary Fund. Roger Lagunoff is Professor of Economics at Georgetown University. 


\section{Contents}

Page

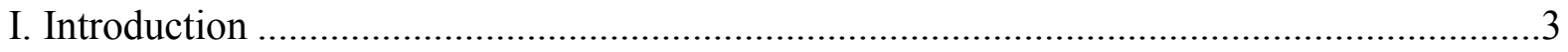

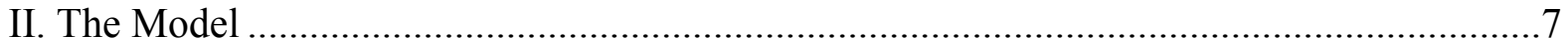

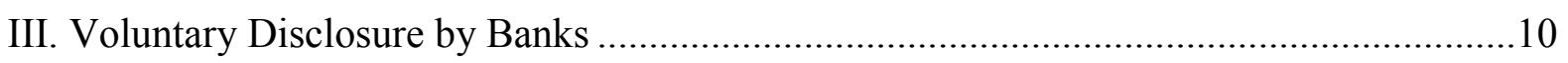

IV. Central Bank Auditing and Disclosure ................................................................. 16

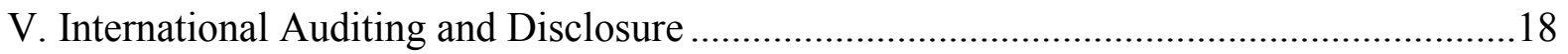

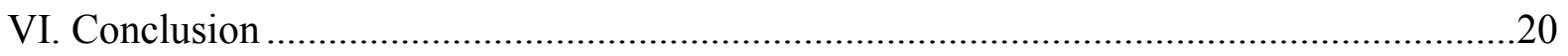

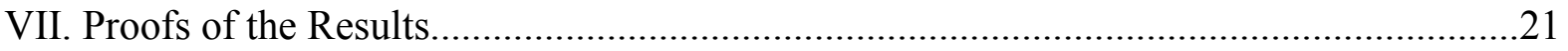

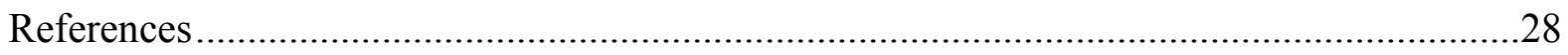




\section{Introduction}

The aim of this paper is to analyze alternative ways to prevent depositor losses from bank insolvencies. There is a general view within the current literature on the "new financial architecture" that openness and transparency in reporting bank balance sheets, as well as other financial data, is a key element in preventing such insolvencies. To quote Eichengreen (1999), "For financial crises, as for health maintenance, prevention is the better part of the cure... Better information on the economic and financial affairs of governments, banks, and corporations will strengthen the market discipline... and help policymakers to identify the need for corrective action."

It is, however, unclear, just how such transparency can be achieved. For one thing, why should banks, in the absence of some regulatory or auditing agency, willingly provide truthful information about their financial situation? Since risk-averse depositors usually prefer to avoid high risk banks with shaky balance sheets, one could easily see that there are large incentives for those banks to misrepresent their balance sheets. However, without accurate and credible information, the repurcussions for investment and hence real income growth could be severe.

There are two current approaches to the issue of bank insolvencies with international repercussions. The first of these is the sovereign debt restructuring mechanism (SDRM). This is essentially a cooperative mechanism that is supposed to give debtors and creditors incentives to restructure unsustainable debt. ${ }^{1}$ Among the many characteristics of this mechanism is the notion that it would allow a debtor country and a majority of its creditors to reach a restructuring agreement that would be binding on all of its creditors. Thus there would be no side deals or holdouts. Another characteristic of the SDRM is that it should deter litigation. This would happen because anything that a creditor were to receive by litigation would be deducted from the claims he might receive under a restructuring agreement.

A second, related approach would be to have an international bankruptcy court. ${ }^{2}$ This court would have certain enforcement powers, in much the same way as a domestic bankruptcy court has some powers. Given the sovereignty of debtors, the international court would almost certainly have less power than would a domestic court over domestic debtors. The most basic, intuitive idea of the role of the court is, as above, that it could introduce a standstill, after a default or potential default, and thereby prevent a country run. Thus a Diamond and Dybvig (1983) style panic would be avoided. In addition, the court would have the power to prevent creditors from forcing repayment, thereby destroying the debtor economy.

\footnotetext{
${ }^{1}$ See, for example, "Proposals for a Sovereign Debt Restructuring Mechanism (SDRM): A Fact Sheet", January 2003 on the IMF website. This discusses the characteristics and possible benefits of an SDRM.

${ }^{2}$ This is described in Eaton (2002), Krueger (2001), and Rogoff and Zettelmeyer (2002), among other places.
} 
Naturally, a more detailed description of the SDRM and the international bankruptcy court ideas would be considerably more complex than what we have given above. Nonetheless, a key characteristic of both of these related mechanisms is that they are essentially backwards looking. That is, they are designed to remedy failures after the failures have occurred. Of course, arguments can be made that the existence of the relevant international institutions may reduce tendencies of banks to fail. Still, these mechanisms do not provide an obvious channel for depositors to avoid potentially failing banks, or, indeed, for banks to be deterred from overly risky behavior.

So what is needed to both reduce the likelihood of bank failures as well as improve the welfare of the economy? Kletzer (1984) provides some guidance on this issue. He emphasizes the importance of debt data for the efficient functioning of markets. On the other hand, such data is generally not available, or if available is not reliable. To quote Eaton (2002), "A deficiency more glaring and immediate than the absence of an international bankruptcy court is the absence of a data authority providing timely and accurate information on sovereign debt... The World Bank in its participation in the HIPC [Heavily Indebted Poor Country] initiative to provide very poor countries relief from official debt conducts a comprehensive debt inventory. This methodology should be extended to all sovereign debtors and should apply to debts from both official and private sources."

Who should provide such information? One possibility would be private rating agencies or private auditors who might give risk assessments of banks. As the recent experience of Enron and others shows, there is a significant risk that such auditors will be captured by their clients. Also, from a purely modeling perspective, it is difficult to explain why private auditors would offer information on all banks in all countries. That is, how should their profit motive be determined? In addition, it would be quite difficult to model the depositors', or banks', payments to auditors who may have different national coverages. Accordingly, we will focus only on auditing by non-profit-maximizing public agencies, using the following approach.

This paper develops a simple model of deposit behavior with bank insolvencies. Its central focus is on the provision of information and its effect on the deposit behavior of consumers. In the model, there is a continuum of identical depositors. Depositors have two consumption dates. Initially, they allocate their first period income between present consumption and bank deposits for future consumption. Their deposits can be spread among $J$ ex ante identical banks. Hence, depositors face a standard portfolio decision. They desire to smooth both across time and across banks. Both banks and consumers are potentially spread across the globe. Each bank offers a promised rate of return on its deposits. However, banks' investments are risky, and so the promised return is subject to possible default. After the investment opportunities are identified, banks receive idiosyncratic, privately observed signals of the actual risk characteristics of their potential investments. These signals assess the probability that a bank can make good on its promises. We refer to the bank's signal as its solvency type. A bank's solvency type could, in principle, be uncovered and disclosed 
by an auditor who properly investigates the bank's balance sheets.

We do not, however, assume that such credible disclosure by formally independent auditors is automatic. Hence, the disclosure incentives of the auditor are object of the analysis. Specifically, our aim is to analyze the disclosure incentives of two alternative institutions of bank auditing. The first institution is one in which a central bank's job is to verify the information provided by national banks in its country in order to disseminate estimates of risk to depositors. We call this institution the central bank disclosure regime. In the second type of institution, audits will be carried out by an international agency that collects risk information on banks in all countries, and provides it to depositors. We call this the international disclosure regime. As a baseline, we compare both regimes to a default: the voluntary disclosure regime in which banks self-report.

In each of the institutions, the solvency type of each of the banks is subject to disclosure. Using the language of the literature on cheap talk dating back to the seminal work of Crawford and Sobel (1982), the present model would be classified as a multiple sender model of cheap talk. ${ }^{3}$ We borrow heavily from the, by now standard, techniques developed in the cheap talk literature.

The timing is as follows. First, banks offer promised rates of return and receive their private signals of risk. Next occurs the disclosure of this risk, whatever is the source of disclosure. Finally, depositors make their portfolio decisions.

Both the domestic central banks as well as the international auditor include consumers and private banks in their objective functions. An auditor's bank bias is the welfare weight that the auditor assigns to the banks relative to the depositors. In each of these institutions, the disclosure incentives in a symmetric, Perfect Bayesian equilibrium are summarized by a disclosure rule, a mapping from solvency types to messages.

We measure the performance of a disclosure rule in each of these institutions by measuring its richness. Roughly, one disclosure rule is richer than another if it induces more information states, i.e, induces more steps, than its alternative. On its own, the notion of richness is a rather weak ordering of information. Yet, it nevertheless carries implications for the depositors' welfare. Specifically, a result of Crawford and Sobel (1982) applied to this environment shows that depositors are always better off ex ante under richer disclosure rules in equilibrium.

Our main result establishes the superiority of international auditing, other things equal. The international auditor is shown to be at least as informative - in the sense of richness of its disclosure - as that of a corresponding central bank auditor with the same bank bias.

\footnotetext{
${ }^{3}$ However, our work differs from some most other multi-sender models that we know of. For instance, Krishna and Morgan (2001) examine a model in which different experts send messages on common information which is unobserved by the decision maker. By contrast our senders in each institution are disclosing different, uncorrelated, bits of information to the decision maker - the depositor.
} 
Moreover, for some types of bank bias, the international auditor is strictly more informative than the corresponding central banks. Consequently, depositors are better off ex ante under international auditing, other things equal. Not surprisingly, disclosure rules in both auditing institutions are more informative than the voluntary disclosure benchmark.

Significantly, the results do not assume that the international auditor has any informational advantage. Nor is the international auditor somehow less "corrupt" than the central banks. Rather, the international auditor's credibility comes from the simple fact that its incentives are not distorted by a sovereignty bias that plagues the central banks. Without the sovereignty bias, an international auditor exaggerates less the solvency type of any particular bank, because a bank with artificially inflated solvency rates attracts funds away from more truly productive banks.

We believe the results carry particular significance since we would claim that there is a much greater likelihood that auditing could be implemented than, for example, an international bankruptcy court could be. The bankruptcy court, or as a special case an SDRM, would have enforcement powers beyond anything currently seen in the world. Our auditors would have no enforcement power, but would function only as providers of information. Additionally our model will be forward looking in the sense that it describes a system that may prevent future crises. This is thus quite unlike the bankruptcy court concept, that acts primarily as a remedy to insolvencies that have already occurred.

There is relatively little work on policy instruments to prevent bank failures. Morris (2003) considers a framework in which some financing from an international agency, although it may be less than the value of a country's indebtedness, may bring about an inflow of capital, thereby avoiding default. The role of information and an international bankruptcy court is considered in Eaton (2002), although not in the context of a specific model. Blejer, Feldman, and Feltenstein (2002) use a simulation model to examine the effects of monetary and fiscal instruments that react to bank failures. Kletzer and Wright (1999) develop a model which shows how sovereign debt can be sustained in the absence of legal sanctions, if a default were to occur. Kletzer (1984) looks at asymmetric information and its implication for the borrowing of developing countries.

There is a modest literature on accountability in other areas of government. For instance Persson, Roland, and Tabellini (1997) and Maskin and Tirole (2001) study electoral accountability in its relation to separation of powers in governance. Lagunoff (2002) examines executive transparency when governments are dynamically inconsistent decision makers. Laffont and Martimort (1999) examine the role of multiple regulatory agencies in achieving transparency. The present paper is closest in spirit to the last two. As in the Laffont and Martimort (1999) paper, the accountability of a regulatory oversight process is also the central focus of this paper. As in the model by Lagunoff (2002), we focus on the problems of disclosure incentives rather than, say, problems of verifiability. 


\section{The Model}

We now construct a streamlined model which exhibits two critical features. First, deposits are essential in order for banks to make investments. Second, privately observed asymmetries in the effectiveness with which each bank can put deposits to good use creates a demand for accurate disclosure.

There is a single consumption good and two consumption dates. A global market exists with $J$ ex ante identical commercial banks and a continuum of identical, risk-averse investors (or "depositors"). The commercial banks are classic financial intermediaries: each commercial bank $j=1, \ldots, J$ identifies investment opportunities and offers an interest rate $r_{j}$ to attract deposits which, in turn, are used to fund these investment opportunities. For their part, depositors use the banks as vehicles to save in order to smooth across the two consumption dates.

Significantly, the depositors are not concentrated in any particular country. Nor do they limit their deposits to the banks in their own countries. Hence there is no sovereignty bias in the decisions of depositors and banks. Depositors search globally for the optimal returns on their deposits, and each bank's interest rate is available for all depositors worldwide.

Depositors' preferences are represented by the utility function

$$
\log \left(c_{1}\right)+\delta \log \left(c_{2}\right)
$$

for consumption stream $\left(c_{1}, c_{2}\right)$. In the first consumption date, each depositor must choose how much of his income $I_{1}$ to consume and, alternatively, how much to invest in each of the $J$ commercial banks. Let $k_{j}$ denote the amount a representative depositor chooses to deposit in bank $j=1, \ldots, J$, and let

$$
k=\left(k_{1}, \ldots, k_{J}\right)
$$

denote the profile of deposits across the $J$ banks. With these deposits the depositor consumes $c_{1}=I_{1}-\sum_{j=1}^{J} k_{j}$ in the first period. A deposit of $k_{j}$ in the first period yields a promise by the bank to pay $\left(1+r_{j}\right) k_{j}$ in the second period, where $r_{j}$ is the interest rate promised by bank $j$. Essentially, the depositor's investment amounts to a purchase of a one-period bond. In the second consumption date, the depositor has income $I_{2}<I_{1}$, which is assumed to be small enough relative to $I_{1}$ so that the depositor has a desire to save. He consumes both $I_{2}$ and the return $\left(1+r_{j}\right) k_{j}$ from a bank $j$ if that bank can make good on its promise.

The commercial banks form an oligopolistic industry. Banks post interest rates, identify investment opportunities, and collect deposits to make those investments. The specifics of a bank's investment behavior are not modeled in detail here; however, it is critical to note that banks require deposits in order to make investments. Any commercial bank invests the deposit $k_{j}$ in assets which, if there is no default, produce $A k_{j}$ the following period where 
$A>1$. Armed with this production technology, a bank $j$ that fulfills it's promise has a net return of $\left[A-\left(1+r_{j}\right)\right] k_{j}$ on its deposits.

All banks are ex ante identical when they post their interest rates. The profile of posted interest rates is

$$
r=\left(r_{1}, \ldots, r_{J}\right)
$$

After the rates have been posted, the banks become aware of the actual risk characteristics of some of their investment opportunities. There is some chance that bank $j$ (fully) defaults on its promised return of $\left(1+r_{j}\right) k_{j}$ the following period. A random variable, $\theta_{j}$, describes the solvency likelihood of bank $j$ before the second consumption date. Specifically, $1-\theta_{j}$ is the probability of (full) default by the bank $j$ before the next consumption date. Since $\theta_{j}$ is the likelihood of non-default, we will refer to $\theta_{j}$ as bank $j$ 's solvency rate. Hence, a bank of solvency rate $\theta_{j}$ has an expected net return of

$$
\Pi_{j}\left(k_{j}, \theta_{j}, r_{j}\right)=\theta_{j}\left[A-\left(1+r_{j}\right)\right] k_{j} .
$$

Note that while $\theta_{j}$ does affect the expected net return, it does not affect the bank's interest rate decision.

A bank's solvency rate is its type. Solvency rate $\theta_{j}$ of bank $j$ is assumed to be iid across banks, and has distribution $F$ on finite support $[0,1] . F$ is assumed to be common knowledge among all agents in the model. Once the solvency rates are realized, the $J$ commercial banks constitute a "differentiated products" oligopoly as they are differentiated by their solvency rates. The profile of solvency rates is

$$
\theta=\left(\theta_{1}, \ldots, \theta_{J}\right)
$$

If depositors' had full information about $\theta$ his payoff would be

$$
U(k, \theta, r)=\log \left(I_{1}-\sum_{j} k_{j}\right)+\delta E\left[\log \left(I_{2}+\sum_{j} k_{j}\left(1+r_{j}\right)\right) \mid \theta, r\right]
$$

where the expectation is taken with respect to the $k_{j}$ s that disappear with according to default probability $1-\theta_{j}$.

It is assumed, however, that the realized solvency rate $\theta_{j}$ for bank $j$ is not observed by the depositor. In the absence of any information about a bank's solvency rate, the depositor only knows its ex ante distribution, $F$. Depositors therefore require accurate disclosure of the solvency rate in order to make effective savings decisions.

Hence, disclosure in this model concerns disclosure about solvency type. That is, disclosure concerns information about potential balance sheets based on the investment opportunities the bank has identified. In the real world, of course, bank behavior takes place in real time. Banks invest existing deposits that, in turn, produce actual balance sheets 
that may be, hopefully, made available to future depositors before they make their deposit decisions. Incorporating this dynamic recursive feature about the world would complicate the model without revealing much more about disclosure incentives. (However, it may be a useful topic for future research on growth implications.)

We do not model all sources of disclosure. One obvious baseline case is voluntary disclosure by the banks themselves. Another possibility is that disclosure comes from the central banks, each of which audits its own member banks. Central bank disclosure is institutionalized in some countries such as the U.S., but it is not universal. Still a third possibility is that an international auditor audits all the banks and discloses the information.

The incentives for accurate disclosure are the subject of later sections in the paper. Whatever its source, let $m_{j}$ denote the disclosed information about bank $j$ 's solvency rate. We will refer to $m_{j}$ as the message or report on bank $j$. A profile of reports on all banks is given by $m=\left(m_{1}, \ldots, m_{n}\right)$. In an equilibrium (to be defined shortly), the type of information gleaned from a report $m_{j}$ depends on the disclosure rule chosen in equilibrium.

Given a disclosure rule, the timing is as follows. First, banks post interest rates. Solvency rates are then privately realized. Next, disclosure, whatever its source, potentially yields some information about solvency rates to the depositors. Finally, depositors make their savings decisions. This timing is summarized in Figure 1.

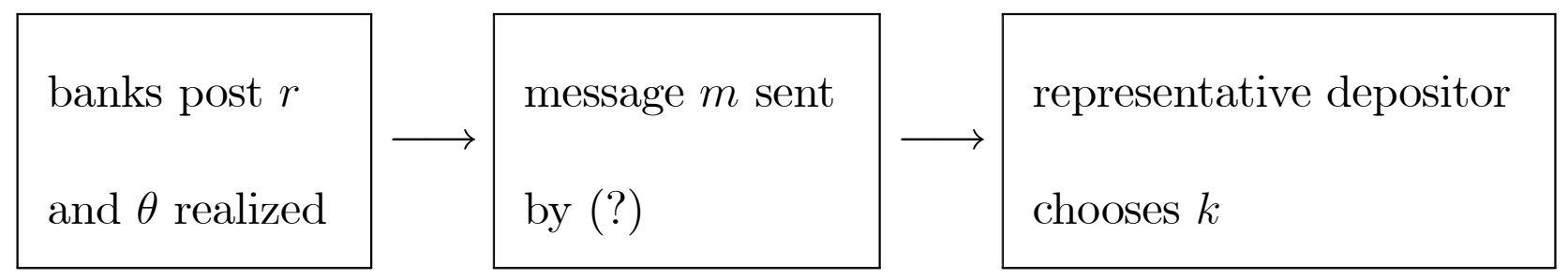

Figure 1

The "(?)" in the time line above represents the source of external disclosure. In Sections 3-5, this source is either the banks themselves, or the central banks that oversee the activities of certain of these commercial banks, or an international auditor that oversees the activities of entire system.

In the following section, we take up the baseline case in which disclosure, or lack thereof, is the voluntary decision of banks. Though this case is not so interesting in and of itself, it provides a useful baseline with which develop the ideas and notation that will be used for later sections. 


\section{$3 \quad$ Voluntary Disclosure by Banks}

We now examine the disclosure in more detail. Of particular interest is incentives for credible disclosure. To begin, suppose that each bank can choose whether or not to reveal its solvency rate. We refer to this as voluntary disclosure regime. Working backwards, we define the strategy rules and equilibria for the voluntary disclosure regime.

\subsection{Decision Rules}

The depositors are the last decision makers. Since the representative depositor does not observe $\theta$, he must update based on the external message profile $m$. Let $\bar{F}(\theta \mid m)$ denote his posterior distribution of types given a message $m$. In equilibrium, $\bar{F}$ is updated using Bayes rule wherever possible. The depositor's objective then is

$$
\max _{k} \int U(k, \theta, r) d \bar{F}(\theta \mid m)
$$

where $U$ is defined by the expression in (2) and where information is updated according to conditional distribution $\bar{F}$ given the external message, $m$. The depositors' deposit decision rule is given by a vector

$$
\Phi=\left(\Phi_{1}, \ldots, \Phi_{J}\right)
$$

where $\Phi_{j}(m, r)=k_{j}$ is the depositors' investment in bank $j$ given interest rates $r$ and given external message profile $m$. The profile $\Phi$ is symmetric if the depositor invests the same amount in two banks whenever he faces the same interest rates and messages for the two.

In the previous stage, each of the banks choose a message $m_{j}$ contingent on its solvency type, $\theta_{j}$. A disclosure rule for bank $j$ is a map $\mu_{j}$ from the set of solvency types, $[0,1]$, to a set of possible messages or reports that could be published or otherwise made available to all depositors. Formally, let $m_{j}=\mu_{j}\left(\theta_{j}\right)$ denote the message sent to depositors concerning bank $j$ 's solvency type. For now we restrict attention to disclosure rules that are weakly increasing in the solvency rate. This restriction is intuitive and still allows for a rich class of disclosure possibilities.

Let $\mu=\left(\mu_{1}, \ldots, \mu_{J}\right)$. For each profile of solvency rates, $\theta$, a profile,

$$
\mu(\theta)=\left(\mu_{1}\left(\theta_{1}\right), \ldots, \mu_{J}\left(\theta_{J}\right)\right)=\left(m_{1}, \ldots, m_{J}\right)=m
$$

of messages is sent to reveal solvency information about the banks. A symmetric disclosure rule is one in which $\mu_{j}=\mu_{i}$ for all $i, j$ pairs of banks.

Given a deposit rule $\Phi$, the banks may be viewed as engaged in a Bayesian game of disclosure in which each choice $\mu_{j}$ is made given the correctly anticipated disclosure rule 
$\mu_{-j}$ of the other banks. Consequently, for each solvency type $\theta_{j}$ of bank $j$ its disclosure rule is chosen to solve

$$
\max _{m_{j}} \int \Pi_{j}\left(\Phi_{j}\left(m_{j}, \mu_{-j}(\theta), r\right), \theta_{j}, r\right) d F
$$

Finally, in the initial stage, banks compete by posting interest rates to attract deposits. Given an anticipated disclosure rule $\mu$ and an anticipated deposit rule $\Phi$, each bank $j$ chooses its interest rate $r_{j}$ to maximize its expected net return given the anticipated interest rate profile $r_{-j}$ of the banks:

$$
\max _{r_{j}} \int \Pi_{j}\left(\Phi_{j}(\mu(\theta), r), \theta_{j}, r\right) d F
$$

where $\Pi_{j}$ is defined by the expression in (1).

\subsection{Ranking Information}

Before proceeding with the equilibrium, a review of various ways of ranking of the disclosure rules will prove helpful.

The following definitions are standard. A disclosure rule $\mu_{j}$ for bank $j$ is perfectly informative if it is a strictly monotone function of $\theta_{j}$. Notice, in this case, that the depositor can infer precisely the true solvency rate by simply inverting the function $\mu_{j}$, which, in equilibrium, he/she anticipates correctly. Without loss of generality, we can always assume that if a perfectly informative disclosure rule is used, the rule is, in fact, the identity, $\mu_{j}\left(\theta_{j}\right)=\theta_{j}$. A rule is uninformative if $\mu_{j}$ is a constant function. In that case the same message is sent regardless of the bank's true solvency type. Finally, a rule will be called partially informative if $\mu_{j}$ is a step function. ${ }^{4}$ Partially informative disclosure rules, as illustrated in Figure 2, are characterized by cut-off types. For example, in Figure 2 the cut-offs, $a_{1}, a_{2} \ldots$, for one of the disclosure rules correspond to types that are indifferent between reporting the message on the lower and on the upper steps.

Given two disclosure rules, $\mu_{j}$ and $\hat{\mu}_{j}$, the rule $\mu_{j}$ is more informative than $\hat{\mu}_{j}$ if the information partition on $\theta_{j}$ induced by $\mu_{j}$ is strictly finer than the one induced by $\hat{\mu}_{j} .{ }^{5}$ Clearly, this standard ordering of informativeness is partial: some pairs of disclosure rules cannot be compared this way.

\footnotetext{
${ }^{4}$ This definition evidently rules out intermediate cases in which the rule can be perfectly revealing over some range, and partially revealing over others. However, when there is a single bank, a well-known result of Crawford and Sobel (1982) applies which show that all equilibrium disclosure rules are partially informative step functions. Though we do not prove it, we conjecture that their result holds in our environment as well.

${ }^{5}$ Hence, for any Borel subset $B \subseteq[0,1]$ and message $m_{j}$ such that $B=\mu_{j}^{-1}\left(m_{j}\right)$, there exists a message $m_{j}^{\prime}$ such that $B \subseteq \hat{\mu}_{j}^{-1}\left(m_{j}^{\prime}\right)$.
} 
Messages

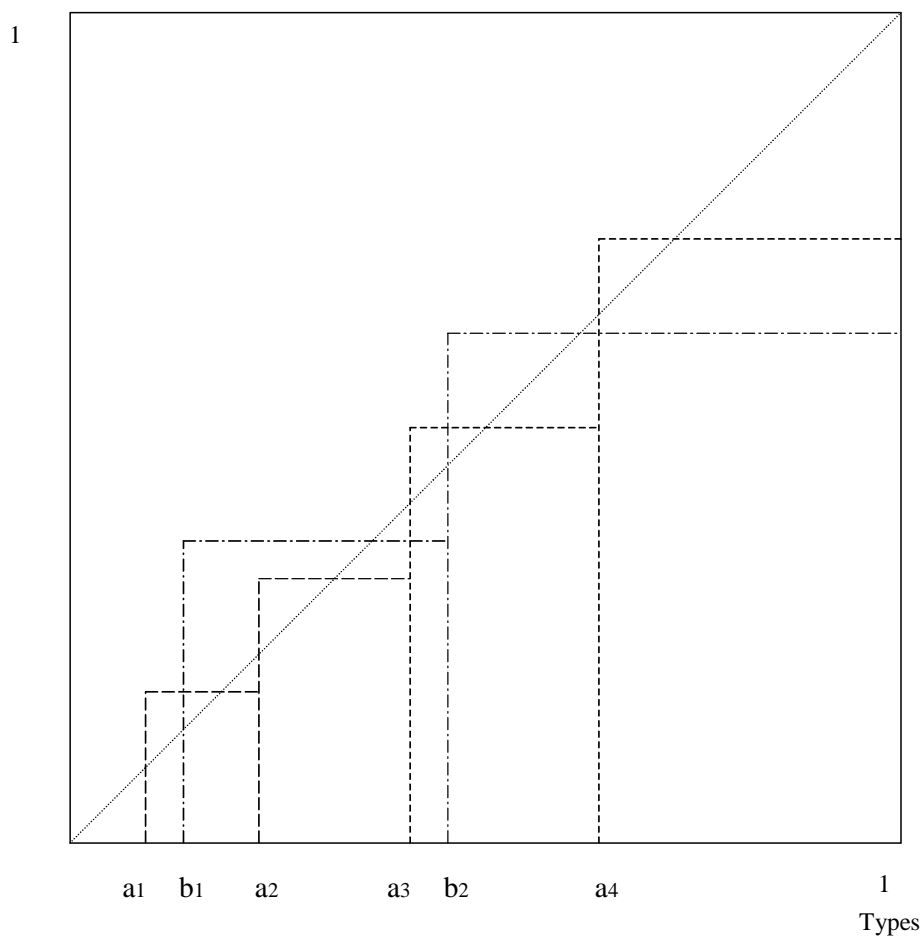

Figure 2: Disclosure rule $\mu_{a}$ is richer than disclosure rule $\mu_{b}$

A weaker notion will prove more useful when comparing auditing regimes. We will say that the rule $\mu_{j}$ has richer information than $\hat{\mu}_{j}$ if the number of distinct messages induced by $\mu_{j}$ exceeds that of $\hat{\mu}_{j}$, that is if $\left|\mu_{j}([0,1])\right|>\left|\hat{\mu}_{j}([0,1])\right|$. For example, $\mu_{j}$ has richer information than $\hat{\mu}_{j}$ if the latter is a constant function, and the former gives distinct values on $[0,1 / 2)$ and $[1 / 2,1]$. Figure 2 displays two partially informative disclosure rules. Disclosure rule $\mu_{a}$ with cut-offs in message space given by $a_{1}, a_{2}, a_{3}, a_{4}$ is clearly richer than disclosure rule $\mu_{b}$ with cutoffs $b_{1}, b_{2}$.

It is easy to show that if $\mu_{j}$ is more informative than $\hat{\mu}_{j}$, then $\mu_{j}$ also has richer information than $\hat{\mu}_{j}$. However the converse does not generally hold. In richer disclosure rules the messages are more meaningful in the sense that they reveal, on average, a smaller diversity of possible solvency rates allowing more accurate targeting of the depositor's investment. More importantly, a result of Crawford and Sobel (1982) implies that richer disclosure rules are always preferred, ex ante, by the depositor (Theorem 3, p. 1448, in C-S, (1982)). That is, if $\mu_{j}$ also has richer information than $\hat{\mu}_{j}$, then

$$
\int U(\Phi(\mu(\theta), r), \theta, r) d F \geq \int U(\Phi(\hat{\mu}(\theta), r), \theta, r) d F
$$


We refer to this property by which richer disclosure rules can be ordered as the CrawfordSobel (C-S) Property.

\subsection{Equilibrium}

A symmetric Perfect Bayesian equilibrium (PBE) of the voluntary disclosure regime is a triple, $\left(\mu, \Phi, r^{*}\right)$, such that $(i)$ the depositor's rule $\Phi$ is symmetric and maximizes (3) given $r$ and $m$; (ii) disclosure profile $\mu$ is symmetric and each bank's disclosure profile $\mu_{j}$ maximizes (4) given $\Phi$ and $\mu_{-j}$; (iii) interest rate profile $r$ is symmetric and each bank's rate $r_{j}^{*}$ maximizes (5) given the depositor's rule $\Phi$, the disclosure rule $\mu$, and other banks' interest rates $r_{-j}^{*}$, and finally (iv) $\bar{F}$ satisfies Bayes rule for all $m$ in the support of $\mu{ }^{6}$

There always exists symmetric PBE of the voluntary disclosure regime in which the disclosure profile is uninformative. For if the depositor believes that messages convey no information, then $\Phi$ is constant over message profiles. In that case, profits of the banks are constant across message profiles as well.

Fix a symmetric PBE, $\left(\mu, \Phi, r^{*}\right)$. To see how disclosure decisions affect deposit behavior in this equilibrium, observe, first, that since the disclosure of a bank's solvency rate is chosen independently of the disclosure of any other bank, then for any equilibrium path message profile, $m$, (i.e., any $m$ in the range of $\mu$ ), the contents of an equilibrium message can always be renormalized to satisfy

$$
m_{j}=E\left[\theta_{j} \mid m_{j}\right]=\int \theta_{j} d \bar{F}_{j}\left(\theta_{j} \mid m_{j}\right)
$$

Naturally, Equation (7) must be consistent with the explicit disclosure rule in equilibrium.

Next, observe that the message profile $m$ in equilibrium induces a distribution on the set $S$ of banks that end up solvent after the default risks are realized. The probability that the set $S \subseteq\{1, \ldots, J\} \cup \emptyset$ comprises those banks that are solvent given information $m$ and $r$ is the generalized binomial:

$$
\operatorname{Pr}(S \mid m)=\prod_{j \in S} m_{j} \prod_{i \notin S}\left(1-m_{i}\right)
$$

${ }^{6}$ Formally, if $m$ is in the support of $\mu$, then $\bar{F}$ is defined by

$$
\bar{F}(\theta \mid m)=\frac{\int_{\left\{z \in \mu^{-1}(m): z \leq \theta\right\}} d F}{\int_{z \in \mu^{-1}(m)} d F}
$$

For out of equilibrium messages, certain consistency conditions apply. See Fudenberg and Tirole (1991) for a standard reference. 
Consequently, if $(m, r)$ are a pair that appears on the equilibrium path, then for each bank $j, j=1, \ldots, J, \Phi_{j}(m, r)$ implicitly solves the depositor's first-order condition for an interior optimum in deposit $k_{j}$ given $\Phi_{-j}$. This first-order condition is given by:

$$
\begin{aligned}
\frac{1}{I_{1}-\sum_{i=1}^{J} k_{i}}-\delta m_{j} \sum_{\{S: j \notin S\}} \operatorname{Pr}(S \mid m)\left[\frac{1+r_{j}}{I_{2}+k_{j}\left(1+r_{j}\right)+\sum_{i \in S} k_{i}\left(1+r_{i}\right)}\right] & \leq 0, \text { and } \\
& =0 \text { if } k_{j}>0
\end{aligned}
$$

We let $\Phi_{j}^{*}(m, r)$ denote the implicit solution to (9) for any pair $(m, r)$ including outof-equilibrium pairs of message and interest rate profiles. Clearly, $\Phi_{j}(m, r)=\Phi_{j}^{*}(m, r)$ for equilibrium path pairs $(m, r)$.

The intuition behind Equation (9) is not subtle. It states roughly that the depositor allocates funds to bank $j$ such that the marginal utility of consumption in the first period is equal to the expected marginal utility of consumption after investment $k$ in the second period. Notice that the left-hand side of this equation is common to all banks and is increasing in $k_{j}$ for each $j$. Hence the right-hand sides of this condition are equal for all banks that receive deposits. That is, the expected marginal utility in the second period from increasing the deposit in bank $j$ is equal to that of bank $i$.

To summarize, we have

Lemma For any symmetric Perfect Bayesian equilibrium $\left(\mu, \Phi, r^{*}\right)$ of the voluntary disclosure regime, the profile $\Phi$ satisfies: for each bank $j$, and each equilibrium path $(m, r)$, $\Phi_{j}(m, r)=\Phi_{j}^{*}(m, r)$, where $\Phi^{*}$ is the implicit solution to Equation (9). In particular, $\Phi_{j}^{*}(m, r)$ is weakly increasing and concave in $m_{j}$ and weakly decreasing in $m_{-j}$. And, if $\Phi_{j}^{*}(m, r)>0$, then it is a differentiably increasing and concave function of $r_{j}$.

A symmetric Perfect Bayesian equilibrium deposit rule $\Phi_{j}$ for bank $j$ is illustrated in Figure 3. The deposit rule $\Phi_{j}$ in Figure 3 coincides with $\Phi_{j}^{*}$ along the equilibrium path. We will call an equilibrium maximally informative if there is no other equilibrium with disclosure profile, $\mu^{\prime}$, such that $\mu_{j}^{\prime}$ has at least as rich information as $\mu_{j}$ for each bank $j$, and has richer information for some bank $j$.

Is there an equilibrium in which voluntary disclosure rule is informative? The following result answers in the negative - which is not too surprising. However, it serves as a useful 
Deposits in Bank j

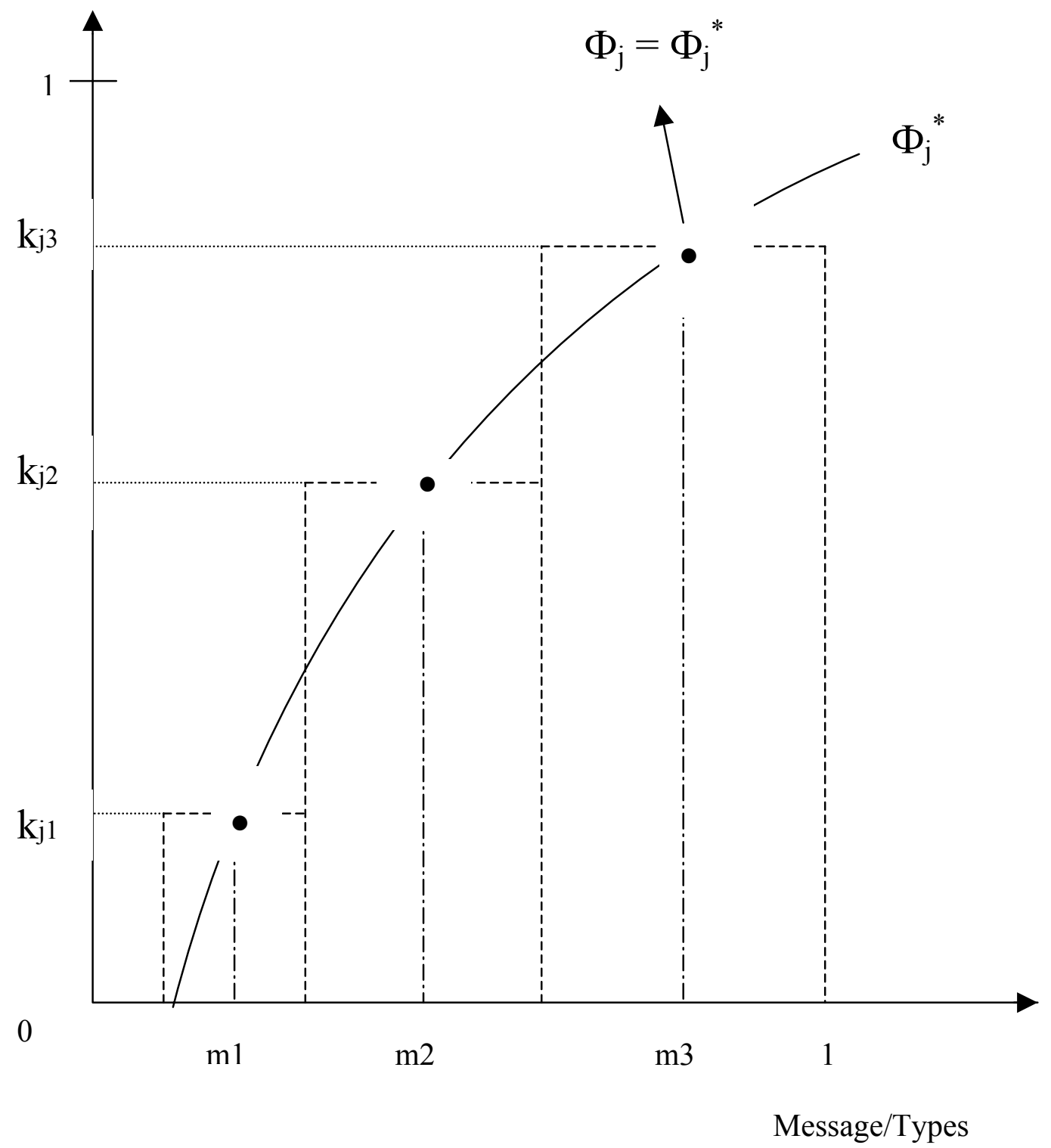

Figure 3: A symmetric Perfect Bayesian equilibrium deposit rule 
benchmark for subsequent results.

Proposition 1 Let $\left(\mu, \Phi, r^{*}\right)$ be a maximally informative symmetric equilibrium of the game with voluntary disclosure. Then each $\mu_{j}$ is uninformative. Consequently, deposit rule induces an identical deposit in each bank $j$ :

$$
\Phi_{j}\left(m, r^{*}\right)=\frac{\lambda I_{1}}{J}, \forall m
$$

where $\lambda$ is an overall savings rate. The savings rate $\lambda$ then satisfies the first-order condition

$$
\frac{1}{I_{1}(1-\lambda)}=\delta m_{0} \sum_{j=0}^{J-1}\left(\begin{array}{c}
J-1 \\
j
\end{array}\right) m_{0}^{j}\left(1-m_{0}\right)^{J-1-j} \frac{1+r^{*}}{I_{2}+(j+1)\left(1+r^{*}\right) \lambda I_{1} / J}
$$

The voluntary disclosure regime therefore produces the same outcomes as if there were no disclosure at all. Consequently, the representative depositor invests equal amounts in all banks. Clearly banks cannot be relied on to self report. Some form of external auditing and disclosure is required.

In the sections that follow, alternative sources of disclosure are explored. However, the same notation and the same equilibrium behavior for the depositor's rule and the banks' interest rate profile apply to these cases as well. The only difference lies in the information content of the disclosure rules.

\section{Central Bank Auditing and Disclosure}

A logical starting point for external disclosure is the central banks that oversee the various commercial banks. We refer to this as the central bank disclosure regime. In each country, a central bank is usually responsible for the oversight of the activities of its member banks. Oversight includes, among other things, auditing the bank's records and disclosing publicly information pertaining to a bank's solvency. A central bank's incentive for credible disclosure is the subject of this section.

Because the main issue in this paper is the disclosure incentives, we do not model the actual costs of auditing. A central bank (CB, from here onward) is assumed to be able to costlessly verify that solvency risk of its bank. Recall that messages sent by external auditors - in this case, CBs - are sent before deposit decisions.

For simplicity assume that each commercial bank belongs to a distinct country. There are then $j$ distinct auditing agencies corresponding to the $j$ central banks. Each central bank has sovereign responsibility for exactly one commercial bank. A central bank must 
therefore weigh the utility of depositors from its own country against the profitability of the member bank in its country. Let $\beta_{j}$ denote the welfare weight placed on banks. We will refer to this weight, $\beta_{j}$, as the central bank's bank bias in its objective function. A higher bank bias indicates that proportionately fewer depositors reside in the central bank's country. If $\theta$ were fully observed, then a central bank with jurisdiction over bank $j$ with bank bias $\beta_{j}$ has the full information payoff:

$$
G_{j}(k, \theta, r)=\left(1-\beta_{j}\right) U(k, \theta, r)+\beta_{j} \Pi_{j}\left(k_{j}, \theta_{j}, r\right)
$$

A lower bank bias $\beta_{j}$ captures the idea that many of depositors come from that central bank's country. The U.S. is an example of a country with high concentrations of depositors. Arguably, its central bank has a lower bank bias then, say, the central bank of the Cayman Islands whose member bank receives deposits mainly from abroad.

Because the central bank audits its member bank, it evaluates the depositor's payoff at the true solvency rate, $\theta_{j}$. When $\beta_{j}=0$, then the CB's payoff coincides with that of the depositor, except that the central bank knows the true solvency rate. When $\beta_{j}=1$ then the central bank from country $j$ has the same payoff as its member bank. The intermediate case is of the most interest.

The central bank is charged with providing information about its member bank's solvency rate.

$$
\int G_{j}\left(\Phi\left(m_{j}, \mu_{-j}\left(\theta_{-j}\right), r^{*}\right), \theta, r^{*}\right) d F_{-j}\left(\theta_{-j}\right)
$$

where the expectation is taken with respect to $m_{j}$ and where $\beta_{j}$ is the central bank's bank bias.

In the following result, we drop the subscript on $\beta_{j}$ for notational convenience.

Proposition 2 Let $\left(\mu, \Phi, r^{*}\right)$ be a maximally informative symmetric equilibrium of the central bank disclosure regime. For each bank $j$, the following holds.

1. If $\beta=1$, then $\mu_{j}$ is uninformative

2. If $\beta=0$, then each $\mu_{j}$ is perfectly informative.

3. There exists a $\bar{\beta} \in[0,1)$ such that for all $\beta>\bar{\beta}$, the maximally informative equilibrium is not perfectly informative. 
4. For any sequence, $\{\beta(t)\}$, such that $\beta(t) \rightarrow \bar{\beta}$ from above, there exists a strictly decreasing subsequence, $\left\{\beta\left(t_{\ell}\right)\right\}$, such that $\mu_{j}$ has richer information the smaller is the weight, $\beta\left(t_{\ell}\right)$ in the subsequence of bank biases.

By the proposition, the incentives for central banks to credibly audit their member banks are, in many cases, dubious at best. Moreover the quality of the audit is related to a central bank's bank bias. Though, Property 4 is not a strict monotonicity result, there is a monotone sequence along which information is richer the smaller is the bank bias. The proof in Section 7 recursively constructs a maximally informative equilibrium. From this construction, one can compute explicitly the maximal number of steps in an equilibrium. One then shows that this number decreases in the bank bias. By the Crawford and Sobel Property that orders richer disclosure rules in Equation (6), richer disclosure profiles are preferred, ex ante, by the depositor. Consequently, the depositor is better off when the bank bias of a central bank is lower.

Since the bank bias measures the lack of domestic investors, the central banks of countries with a smaller number of domestic depositors (along the sequence of bias weights) are the least credible auditors. This is a particular concern for developing countries. Such countries typically do not possess sufficient wealth to have large numbers of domestic depositors. At the same time, sustained development requires investment from abroad. Unfortunately, these are, arguably, the most problematic cases.

Significantly, the problem is not that central banks from developing countries are inherently corrupt. The distortion here is created by natural concerns over the viability of domestic banks to the exclusion of depositors who reside elsewhere. Quite understandably central banks favor domestic concerns, and so their bank biases are possibly exacerbated by a sovereignty bias rather than by corruption, per se.

\section{$5 \quad$ International Auditing and Disclosure}

This section takes up the possibility of an international disclosure regime, i.e., an international institution that performs the auditing functions formerly done by the central banks. The international institution audits all the commercial banks. As before, we examine only the question of disclosure incentives, not the issue of monitoring or verifiability. As with central banks, we assume that auditing is costless and accurate. The question, as with central banks, is: when is the international auditor's reporting credible?

The main difference between the international and domestic auditors is that the former has no sovereignty bias. In particular, it assigns no special status to any specific country or any specific commercial bank. The international auditor has the full information objective 
function

$$
H(k, \theta, r)=(1-\beta) U(k, \theta, r)+\beta \frac{1}{J} \sum_{i} \Pi_{i}\left(k_{i}, \theta_{i}, r\right)
$$

where $\beta$ is the overall bank bias of the international auditor. Because of the natural symmetry of the problem, the specification (12) assumes an implied symmetry in the relative welfare weights between banks. However, we later argue that the main result below can be extended to social objectives with asymmetric weights between banks.

Since the international auditor (IA from here on) audits all the banks, it discloses information simultaneously on the entire profile, $\theta$, of solvency rates. To make sense of this idea, we assume that an international auditor is a multi-divisional organization, with a distinct unit simultaneously auditing each bank. Consequently all audits and disclosures are simultaneous. $^{7}$ We refer to these units as the auditing divisions of the IA.

Let $\mu^{I}$ denote the disclosure rule of the IA. We compare this with the equilibrium disclosure rule, denoted by $\mu^{C}$, in the central bank disclosure regime. Given a solvency rate $\theta_{j}$, the auditing division responsible for bank $j$ chooses message $m_{j}$ to maximize

$$
E\left[H_{j}\left(\Phi^{I}\left(m, r^{*}\right), \theta, r^{*}\right) \mid \theta_{j}, \mu_{-j}^{I}\right]=\int H_{j}\left(\Phi^{I}\left(m_{j}, \mu_{-j}^{I}\left(\theta_{-j}\right)\right), \theta, r\right) d F\left(\theta_{-j}\right)
$$

A symmetric equilibrium of the game with international auditing is a Perfect Bayesian equilibrium, $\left(\mu^{I}, \Phi^{I}, r^{*}\right)$, such that for each realized solvency profile, $\theta,\left(\Phi, r^{*}\right)$ is a symmetric PBE of the game given message profile $\mu^{I}(\theta)$. The same definition of maximally informativeness as with the central bank auditing applies here to $\left(\mu^{I}, \Phi^{I}, r^{*}\right)$.

Our final result compares the international to the central bank disclosure regime.

Proposition 3 Let $\left(\mu^{I}, \Phi^{I}, r^{*}\right)$ be a maximally informative symmetric equilibrium of the international disclosure regime. Let $\left(\mu^{C}, \Phi^{C}, r^{*}\right)$ be a maximally informative symmetric equilibrium of the central bank disclosure regime. Then, for each $\beta$, the disclosure rule $\mu_{j}^{I}$ has (weakly) richer information than the rule $\mu_{j}^{C}$ corresponding to any central bank $j$ with the same bank bias $\beta$. In addition, there is an open set of $\beta$ in $(0,1)$ such that the disclosure rule $\mu_{j}^{I}$ has richer information than the rule $\mu_{j}^{C}$ corresponding to a central bank $j$ with the same bank bias $\beta$.

According to the result, the international auditor is never less credible than a central bank with the bank bias. And for some bank bias weights, the international auditor is more credible than the central bank. As before, the proof is constructive. Maximally informative

\footnotetext{
${ }^{7}$ This also allows a fair comparison between domestic and the international audits. Specifically, we do not "build in" an informational advantage for the international organization's auditing capability. To do so, however, would only strengthen the main results which emphasize the benefits of international auditing.
} 
equilibria in each regime are constructed recursively. Using once again the Crawford-Sobel Property, it turns out that ceteris paribus, international auditing is at least weakly preferred to central bank auditing by the depositor ex ante. Both regimes distort information upward to some extent. Bank solvency is exaggerated. However, it is exaggerated less under international auditing than under central bank auditing.

The critical difference is the sovereignty bias associated with central bank disclosure. An upward distortion in the message of one particular bank's solvency rate has two effects. First, it distorts upward the investment in period two consumption by the depositor. Hence, an upward distortion distorts away from the depositor's optimal smoothing between the two consumption dates. If the bank bias is large enough, however, then even an international auditor does not care about this type of distortion much. However, there is a second effect which the international auditor does care about: an upward distortion in bank $j$ 's solvency rate distorts investment away from more profitable investments in other banks. This second effect is ignored by the central banks due to their sovereignty bias. It is precisely this type distortion which is mitigated by international auditing.

The intuition here indicates that the result is, in a particular sense, robust with respect to changes in implied welfare weights between the banks. Currently, all banks are weighted equally. Suppose, however, some banks were weighted more than others in (12). Suppose that $\alpha_{j}$ is the relative weight given to bank $j$ among the banks. Then Proposition 3 would still be true for a bank $j$ provided that the implied bank bias $\beta \alpha_{j}$ given to bank $j$ by the international auditor is the same as the original bank bias given to that bank by its central bank.

\section{Conclusion}

This paper constructs a model in which an international institution responsible for the auditing of bank solvency performs at least as well, and sometimes better than, auditing by either central banks or of the member banks themselves. The results do not require informational advantages of an international auditor. Nor do they hinge on assumptions of greater honesty or inscrutability by the international auditor. Instead, the results utilize the inherent advantages of a decision maker without a sovereignty bias. Unlike the central banks in most countries, the international auditor does not automatically favor the banks or depositors in any particular country. We show that sovereignty bias can impede incentives for credible disclosure in central banks, particularly in those countries with few domestic investors.

Our results show that the international auditor provides a richer set of information to the depositor than does self-reporting by banks, or auditing of banks by central banks, assuming central banks report only on their national member banks. The results of Crawford and 
Sobel (1982) show that richer disclosure rules are always preferred by depositors to rules with weaker information structures. Accordingly, we have, implicitly, a conclusion that international auditing is welfare improving, as compared to the other mechanisms, in the sense that expected losses of depositors will be lower.

Our conclusions may be viewed as being complimentary to some recent work on bank runs. For example, Peck and Shell (2003) show that for a broad class of deposit contracts, a bank run can occur in equilibrium. Diamond and Rajan (2001), on the other hand, develop a model in which depositors discipline bankers by the threat of a run, and in equilibrium a run does not happen. Our work does not deal with bank runs. However, a mechanism that reduces expected losses would presumably reduce the threat of bank runs. In addition, most of the other work in this area is essentially institution free, in the sense that it lacks regulatory agencies or central bank. The models consist of borrowers, depositors and banks. We would thus claim that our welfare improving auditing mechanism also adds an element of realism to the banking models.

As the analysis focuses on disclosure incentives, other issues such as verifiability and moral hazard are not explored here. Moral hazard of bank behavior, in particular, has been the object of numerous studies. These basically show that banks sometimes take on excessive risk when their decisions are left unexposed. While we do not model the auditing process explicitly, one would expect that sovereignty bias exacerbates moral hazard problems as well. Consequently, moral hazard may also be mitigated by international auditing. These issues are left for future research.

\section{Proofs of the Results}

Proof of the Lemma Suppose, first, that $\Phi_{j}^{*}(m, r)$ is a differentiably increasing and concave function of $r_{j}$, then the bank's objective, (5), is concave in $r_{j}$. Consequently, first-order

conditions are sufficient to characterize optimal decisions for banks. Also, an inspection of the first-order condition (9) for depositors reveals that $k_{j}$ is weakly increasing in $m_{j}$ and weakly decreasing in $m_{i}, i \neq j$.

Next, implicit differentiation of the depositor's first-order condition with respect to in- 
terest rate $r_{j}$ gives

$$
\begin{aligned}
& \frac{\sum_{i=1}^{J} \frac{\partial k_{i}}{\partial r_{j}}}{\left(I_{1}-\sum_{i=1}^{J} k_{i}\right)^{2}}=\delta m_{j} \sum_{\{S: j \notin S\}} \operatorname{Pr}(S \mid m) \\
& \times\left[\frac{\left(I_{2}+\sum_{i \in S} k_{i}\left(1+r_{i}\right)\right)-\left(1+r_{j}\right)\left[\frac{\partial k_{j}}{\partial r_{j}}\left(1+r_{j}\right)+\sum_{i \in S} \frac{\partial k_{i}}{\partial r_{j}}\left(1+r_{i}\right)\right.}{\left(I_{2}+k_{j}\left(1+r_{j}\right)+\sum_{i \in S} k_{i}\left(1+r_{i}\right)\right)^{2}}\right]
\end{aligned}
$$

In order to maintain this equality at every interest rate profile, $r, \frac{\partial k_{j}}{\partial r_{j}}$ must be positive and declining in $r_{j}$. Hence, $\Phi_{j}^{*}$ is positive and concave in $r_{j}$ if it satisfies the interior first-order condition.

To verify monotonicity of $\Phi_{j}^{*}$ in $m_{j}$, observe that the first-order condition for the depositor (i.e., Equation (9) ) may be expressed as

$$
m_{j}=\left[\sum_{\{S: j \notin S\}} \operatorname{Pr}(S \mid m) \frac{\left(1+r_{j}\right)\left(I_{1}-\sum_{i=1}^{J} k_{i}\right)}{I_{2}+k_{j}\left(1+r_{j}\right)+\sum_{i \in S} k_{i}\left(1+r_{i}\right)}\right]^{-1}
$$

In this equation, $m_{j}$ is a strictly increasing, convex function of $k_{j}$. Consequently, an inverse exists and is strictly increasing and concave in $m_{j}$. (Note: this proves that if a function $\Phi_{j}^{*}$ satisfies the first-order condition on all messages $m_{j}$, then it is strictly concave in $m_{j}$ whenever its value is nonzero.) Since $\Phi_{j}^{*}$ satisfies the first-order condition on the disclosed messages, $m_{j} \in \operatorname{supp} \mu_{j}$, it is increasing on these messages.

Proof of Proposition 1 With voluntary disclosure, each bank with solvency rate $\theta_{j}$ chooses its message $m_{j}$ to maximize

$$
\left.\theta_{j} \int_{\theta_{-j}}\left[A-\left(1+r^{*}\right)\right)\right] \Phi_{j}\left(m_{j}, \mu_{-j}\left(\theta_{-j}\right)\right) d F
$$

Notice that any solution to (13) does not depend on the value of $\theta_{j}$. Consequently, the maximizer $m_{j}$ is independent of type regardless of what the depositor believes about the informativeness of the bank's message. Consequently, there is some $m_{j}$ such that for which $\mu_{j}\left(\theta_{j}\right)=m_{j}$ for all $\theta_{j}$. Anticipating this, the depositor infers nothing about the bank's message $m_{j}$ and so $m_{j}=m_{0}$ (recall that $m_{0}$ is the null message). Finally, the portfolio decision in the no-disclosure case is fully characterized by (10) and (11)

Proof of Proposition 2 Let $\left(\mu, \Phi, r^{*}\right)$ be a maximally informative, symmetric equilibrium of the game with central bank auditing. Consider a central bank from country $j$. 
Proof of (1). Suppose that $\beta=1$. The CB cares only about its member bank's profits. Then clearly its objective and the member bank's objective coincide. The previous Proposition therefore applies and so the disclosure rule in uninformative.

Proof of (2). Suppose that $\beta=0$. That is, the CB cares only about the depositors. Suppose, further, that the depositor anticipates a perfectly informative message, i.e., $\mu_{j}\left(\theta_{j}\right)=\theta_{j}$ for every $\theta_{j}$. Given $\theta_{j}$, the CB then chooses $m_{j}$ to maximize

$$
E\left[U\left(\Phi\left(m_{j}, \mu_{-j}^{C}\left(\theta_{-j}\right), r^{*}\right), \theta_{j}, \mu_{-j}^{C}\left(\theta_{-j}\right), r^{*}\right)\right]
$$

Since $\Phi\left(m, r^{*}\right) \in \arg \max _{k} \int U\left(k, \theta, r^{*}\right) d \bar{F}(\theta \mid m)$, the values of the programs of the central bank and the depositor are clearly aligned in expectation (with respect to $m_{-j}$ ) when $m_{j}=\theta_{j}$. Hence, if a perfectly informative disclosure rule, $\mu_{j}\left(\theta_{j}\right)=\theta_{j}$, is anticipated by the depositor, and so $m_{j}=\theta_{j}$ maximizes (14).

Proof of (3). Suppose, by contradiction, that for every $\beta \in(0,1)$, the maximally informative equilibrium is perfectly informative. The depositor then believes that $\mu_{j}$ is perfectly informative, and so $\Phi_{j}$ satisfies the first-order condition, (9) and, by the Lemma, is continuous and strictly increasing in $m_{j}$. Given $\Phi, m_{j}=\theta_{j}$ then maximizes

$$
G_{j}^{\beta}\left(m_{j}, \theta_{j}\right) \equiv \int G_{j}\left(\Phi\left(m_{j}, \mu_{-j}\left(\theta_{-j}\right), r^{*}\right), \theta, r^{*}\right) d F_{-j}\left(\theta_{-j}\right)
$$

where we write $G_{j}^{\beta}\left(m_{j}, \theta_{j}\right)$ to express explicit dependence on the bank bias weight, $\beta$. Clearly, $G_{j}^{\beta}$ is continuous in $\beta$. Let $\bar{m}_{j}^{\beta}\left(\theta_{j}\right)=\arg \max _{m_{j}} G_{j}^{\beta}\left(m_{j}, \theta_{j}\right)$. Recall that, by a step in the proof of the Lemma, $\Phi_{j}$ is strictly concave in $m_{j}$ on all open sets for which the depositor's first-order condition holds. In this case, the supposition that $\mu$ is perfectly informative means that the first-order condition holds everywhere. Consequently, $\bar{m}_{j}^{\beta}\left(\theta_{j}\right)$ is single valued, and by the Theorem of the Maximum, is continuous in $\beta$. By the previous two steps in the proof,

$$
G^{0}\left(\bar{m}^{0}\left(\theta_{j}\right), \theta_{j}\right)=G^{0}\left(\theta_{j}, \theta_{j}\right)=E\left[U\left(\Phi\left(\theta_{j}, \mu_{-j}\left(\theta_{-j}\right), r^{*}\right) ; \theta_{j}, m_{-j}, r^{*}\right)\right],
$$

while

$$
\left.G^{1}\left(\bar{m}^{1}\left(\theta_{j}\right), \theta_{j}\right)=G^{1}\left(1, \theta_{j}\right)=E\left[\Pi_{j}\left(\Phi\left(1, \mu_{-j}\left(\theta_{-j}\right)\right), \theta_{j}, r^{*}\right), r^{*}\right)\right] .
$$

In other words, $\bar{m}^{0}\left(\theta_{j}\right)=\theta_{j}$ and $\bar{m}^{1}\left(\theta_{j}\right)=1$. Consequently, by the Intermediate Value Theorem, there is $0<\bar{\beta}<1$ such that $\bar{m}^{\bar{\beta}}\left(\theta_{j}\right)=m_{j}>\theta_{j}$. Consequently, this is true for all $\beta \geq \bar{\beta}$. In that case, however, the initial supposition that $\mu_{j}$ is perfectly informative cannot constitute an equilibrium disclosure rule, hence, a contradiction. 
Proof of (4). Using the $\bar{\beta}$ in the proof of (3), suppose that $\beta \geq \bar{\beta}$. Then with bank bias $\beta$, the maximally informative equilibrium is either partially informative or uninformative. All such equilibria have the following structure.

First, the deposit rule $\Phi_{j}^{C}$ satisfies, by the Lemma $\Phi_{j}^{C}\left(m_{j}, r^{*}\right) \equiv \Phi_{j}^{*}\left(m_{j}, r^{*}\right)$ whenever $m_{j}$ lies in the range of the disclosure rule $\mu_{j}^{C}$ (and, recall, that $\Phi^{*}$ satisfies the first-order condition, (9) ). Set $\Phi_{j}^{C}\left(m_{j}, r^{*}\right)=0$ for all other values of $m_{j}$. In other words, out of equilibrium messages elicit a belief from the depositor that the bank is of the lowest solvency type. Hence, the depositor invests nothing in that bank.

Fix a disclosure profile, $\mu_{-j}$, for banks other than bank $j$. Let $G_{j}^{\beta}\left(m_{j}, \theta_{j}\right)$ be defined as in Equation (15) This is the expected payoff for central bank $j$ when payoffs are evaluated at messages on the equilibrium path.

Now define:

$$
M(x, y)=\frac{1}{F(y)-F(x)} \int_{x}^{y} z d F=E[z: z \in[x, y)] .
$$

This means that $M(x, y)$ is the message corresponding to the conditional expectation of $z$ given that it lies in the interval $[x, y)$.

The partitions from the best response disclosure rule for central bank $j$ are generated recursive as follows.

$$
g^{\beta}(x, y)=\inf \left\{z: G_{j}^{\beta}(M(x, y), y)=G_{j}^{\beta}(M(y, z), y)\right\}
$$

In words, $g^{\beta}$ selects the right end of the interval $[y, z)$ such that a bank of solvency type $y$ is indifferent between reporting a solvency type in $[y, z)$ and a solvency type in the lower interval $[x, y)$. Hence, the function $g^{\beta}$ defines the partition elements by defining the cut-off types.

Observe that by Steps 3 earlier in the proof, $g^{\beta}$ is continuous in $\beta$. The function $g$ also defines second-order difference equation, $g^{\beta}\left(z_{t}, z_{t+1}\right)=z_{t+2}$.

Let $\gamma^{\beta}$ denote the solution to the difference equation as a function of the number $T$ of iterations and the initial condition, $z_{1}$. That is,

$$
\gamma^{\beta}\left(T, z_{1}\right)=z_{T}
$$

The maximally informative disclosure rule in the central bank auditing also maximizes the number of distinct messages, $T$, consistent with that number satisfying $\gamma^{\beta}\left(T, z_{1}\right)=1$. Hence, the number of messages in a maximally informative equilibrium, expressed as a function of $\beta$ is given by

$$
T^{\beta}=\sup _{z_{1}}\left\{T>0: \gamma^{\beta}\left(T, z_{1}\right)=1,\right\}
$$


By Steps 1-3 in the proof, we therefore have $T^{0}=1$ and $T^{\beta} \rightarrow \infty$ as $\beta \rightarrow \bar{\beta}$. From this latter sequence of $\beta \mathrm{s}$, we may extract a monotone subsequence $\beta(t) \searrow \bar{\beta}$ such that along the sequence, $T^{\beta(t)}$ is increasing in $t$. By construction, then, $\mu_{j}(t)$ has richer information than $\mu_{j}(t-1), \forall t$. This concludes the proof.

Proof of Proposition 3 Consider a bank $j$ with solvency rate $\theta_{j}$. Clearly, if $\beta=0$, then the disclosure rules in both cases are perfectly informative. Suppose then that $\beta>0$.

We use to same characterization of partially informative equilibria as in Step 4 of the proof of the previous result. For notational comparison between the two regimes, we repeat the characterization here.

As before, the deposit rule in either regime, i.e., $\Phi_{j} \in\left\{\Phi_{j}^{C}, \Phi_{j}^{I}\right\}$, by the Lemma, $\Phi_{j}\left(m_{j}, r\right)=\Phi_{j}^{*}\left(m_{j}, r\right)$ whenever $m_{j}$ lies in the range of the corresponding disclosure rule and where $\Phi^{*}$ satisfies the first-order condition, (9). Consequently, if a message $m_{j}$ lies in the range of both disclosure rules, $\mu_{j}^{C}$ and $\mu_{j}^{I}$ for a bank then we must have

$$
\Phi_{j}^{C}\left(m_{j}, r\right)=\Phi_{j}^{I}\left(m_{j}, r\right)=\Phi_{j}^{*}\left(m_{j}, r\right)
$$

As before, then, set $\Phi_{j}\left(m_{j}, r^{*}\right)=0$ for values of $m_{j}$ not in the range of the disclosure rule. Out of equilibrium messages elicit a belief from the depositor that the bank is of the lowest solvency type. Hence, the depositor invests nothing in that bank.

Fix a disclosure profile, $\mu_{-j}$ for banks other than bank $j$, and fix an interest rate profile $r$. Let

$$
G_{j}^{*}\left(m_{j}, \theta_{j}\right) \equiv \int G_{j}\left(\Phi^{*}\left(m_{j}, \mu_{-j}\left(\theta_{-j}\right)\right), \theta, r\right) d F_{-j}\left(\theta_{-j}\right)
$$

and

$$
H_{j}^{*}\left(m_{j}, \theta_{j}\right) \equiv \int H\left(\Phi^{*}\left(m_{j}, \mu_{-j}\left(\theta_{-j}\right)\right), \theta, r\right) d F_{-j}\left(\theta_{-j}\right)
$$

These are the expected payoffs in each auditing regime when payoffs are evaluated as if they are on the equilibrium path.

As before, define

$$
M(x, y)=\frac{1}{F(y)-F(x)} \int_{x}^{y} z d F=E[z: z \in[x, y)] .
$$

This means that $M(x, y)$ is the message corresponding to the conditional expectation of $z$ given that it lies in the interval $[x, y)$.

Again following the construction in Part (4) of the proof of Proposition 2, the partitions from the best response disclosure rules may be generated by the recursive functions,

$$
g(x, y)=\inf \left\{z: G_{j}^{*}(M(x, y), y)=G_{j}^{*}(M(y, z), y)\right\}
$$


and

$$
h(x, y)=\inf \left\{z: H_{j}^{*}(M(x, y), y)=H_{j}^{*}(M(y, z), y)\right\}
$$

In words, $g$ and $h$ select the right end of the interval $[y, z)$ such that a bank of solvency type $y$ is indifferent between reporting a solvency type in $[y, z)$ and a solvency type in the lower interval $[x, y)$. Hence, the functions $g$ and $h$ define the partition elements by defining the cut-off types. ${ }^{8}$

Observe that both $g$ and $h$ are increasing in $x$ and $y$. We prove the Proposition in the following four Steps.

Step 1: First, we show that $h(x, y) \leq g(x, y)$ for all $x, y$, and the inequality is strict whenever $\overline{h(x, y)}<1$.

To prove Step 1, observe that by definition, $H_{j}^{*}\left(m_{j}, z\right)>G_{j}^{*}\left(m_{j}, z\right)$. Next, since $\Pi_{\ell}$ is decreasing in $m_{j}$ for any pair, $j, \ell$, then by the Lemma, $H_{j}^{*}$ and $G_{j}^{*}$ are single peaked, concave in $m_{j}$. Moreover, $\Pi_{\ell}$ is increasing in $m_{j}, j \neq \ell$. Together, these facts imply

$$
\forall z, \frac{\partial G_{j}^{*}\left(m_{j}, z\right)}{\partial m_{j}}>\frac{\partial H_{j}^{*}\left(m_{j}, z\right)}{\partial m_{j}}
$$

According to this inequality, the marginal net benefit to higher reported solvency for bank $j$ is higher under central bank disclosure than under international auditor disclosure.

These last facts imply that, for any message $m_{j}$, if $m_{j}^{\prime}$ and $m_{j}^{\prime \prime}$ are messages that satisfy

$$
G_{j}^{*}\left(m_{j}, \theta_{j}\right)=G_{j}^{*}\left(m_{j}^{\prime}, \theta_{j}\right)
$$

and

$$
H_{j}^{*}\left(m_{j}, \theta_{j}\right)=H_{j}^{*}\left(m_{j}^{\prime \prime}, \theta_{j}\right)
$$

respectively, then

$$
m^{\prime \prime}<m^{\prime}
$$

But then taking $m_{j}=M(x, y)$, the definitions of $g$ and $h$ imply: $g(x, y)=z^{\prime}$ with $m_{j}^{\prime}=$ $E\left[z: z \in\left[y, z^{\prime}\right)\right]$, and $h(x, y)=z^{\prime \prime}$ with $m_{j}^{\prime \prime}=E\left[z: z \in\left[y, z^{\prime \prime}\right)\right]$. Consequently, either $h(x, y)=g(x, y)=1$, or $h(x, y)<g(x, y)$. If $h(x, y)<1$ the latter case holds. This proves Step 1. //

\footnotetext{
${ }^{8}$ The reader will observe that the function $g$ is the same as the definition of " $g^{\beta}$ " in Step 4 of the proof of Proposition 2. Here, however, we suppress the notational dependence on $\beta$.
} 
Step 2: Both $g$ and $h$ define second-order difference equations:

$$
g\left(z_{t}, z_{t+1}\right)=z_{t+2} \text { and } h\left(z_{t}, z_{t+1}\right)=z_{t+2}^{\prime}
$$

By Step 1, $z_{t_{2}}>z_{t+2}^{\prime}$. Let $g^{*}$ and $h^{*}$ denote the solutions to these, as a function of the number $T$ of iterations and the initial condition, $z_{1}$. That is,

$$
g^{*}\left(T, z_{1}\right)=z_{T} \text { and } h^{*}\left(T, z_{1}\right)=z_{T}^{\prime}
$$

The maximally informative disclosure rule in, say, the central bank auditing also maximizes the number of distinct messages, $T^{g}$, consistent with that number satisfying $g^{*}\left(T^{g}, z_{1}\right)=$ 1. Hence, the number of messages, $T^{g}$ and $T^{h}$, each satisfy:

$$
T^{g}=\sup _{z_{1}}\left\{T>0: g^{*}\left(T, z_{1}\right)=1,\right\}
$$

and

$$
T^{h}=\sup _{z_{1}}\left\{T>0: h^{*}\left(T, z_{1}\right)=1,\right\}
$$

Recall that $T^{g}$ and $T^{h}$ are the number of messages sent in maximally informative best responses under central bank and international auditing, respectively. Moreover, if $T^{g}=1$, then the disclosure rule is uninformative. Whereas if $T^{g}=\infty$, then the disclosure rule approximates the perfectly informative disclosure rule. We use these definitions to prove:

$$
T^{h} \geq T^{g}
$$

To prove this claim, observe that $h^{*}\left(T^{g}, z_{1}^{g}\right) \leq g^{*}\left(T^{g}, z_{1}^{g}\right)=1$. Step 2 then follows by definition of $T^{h}$.

This proves that for a given profile, $\mu_{-j}$ for others, the international auditor's best response for bank $j$ has weakly richer information (hence is at least as informative as) than that of the central bank auditor for bank $j$. //

Step 3: Observe that by the previous proposition, $T^{g} \rightarrow 1$ as $\beta \rightarrow 1$. Let $\beta^{C}$ be the smallest bank bias such that central bank auditing of $j$ is uninformative. By definition, the best response of the central bank auditor is not uninformative for all $\beta<\beta^{C}$. Hence, $T^{g}>1$ for all $\beta<\beta^{C}$. For such welfare weights, there exists an initial condition $z_{1}>1$ under $g^{*}$ such that $g^{*}\left(1, z_{1}\right) \leq 1$. Notationally, we can express the initial condition as a function of the welfare weight, i.e., $z_{1}(\beta)$. Consider the limit taken from below,

$$
z_{1}^{-}=\lim _{\beta \uparrow \beta^{C}} z_{1}(\beta)
$$


Then $g^{*}\left(1, z_{1}^{-}\right)=1$, and

$$
G_{j}^{*}\left(M\left(0, z_{1}\right), z_{1}^{-}\right)=G_{j}^{*}\left(M\left(z_{1}^{-}, 1\right), z_{1}^{-}\right)
$$

By Step 1, $h\left(0, z_{1}^{-}\right)<1$. Consequently, there is some $\epsilon>0$ such that for welfare weight $\beta=\beta^{C}-\epsilon$ and corresponding initial condition, $z_{1}(\beta)$, we have $h\left(0, z_{1}(\beta)\right)<1$. But for this $\beta$ we also have $T^{h}>1$. That is, we have established that for small enough $\epsilon>0$, under welfare weight $\beta=\beta^{C}-\epsilon$, international auditing can sustain a partially informative disclosure for bank $j$, whereas central bank auditing sustains only uninformative disclosure for that bank. Hence, there is an open set of bank biases for which IA auditing sustains richer disclosure than for $\mathrm{CB}$ auditing given $\mu_{-j} \cdot / /$

Step 4: Now suppose that $\mu_{-j}$ has richer information than a profile $\hat{\mu}_{-j}$. Let $g$ and $\hat{g}$, and $\bar{h}$ and $\hat{h}$ be the corresponding recursive functions which generate maximally informative disclosure for international and for central bank auditing, respectively. By the Lemma, the depositor's deposit in bank $j$ is smaller under $\hat{\mu}_{-j}$, other things equal. Consequently, richer disclosure of $j$ 's solvency type is required to achieve the same deposit in bank $j$. More precisely, from the definitions of $G^{*}$ and $H^{*}$ and the constructions of $g, \hat{g}, h$ and $\hat{h}$, for each $x$ and $y, h(x, y)<\hat{h}(x, y)$ and $g(x, y)<\hat{g}(x, y)$. But this implies that the partition-defining sequence generated by $\mu_{-j}$ has richer information than that generated by $\hat{\mu}_{-j}$. Using $\mu_{-j}$ for the central bank case, and $\hat{\mu}_{-j}$ for the international auditing, we then repeat Steps 1-3 to show that the resulting $\mu_{j}$ for bank $j$ under international auditing is richer than the resulting $\mu_{j}$ for bank $j$ under central bank auditing. This justifies the initial assignment of $\mu_{-j}$ and $\hat{\mu}_{-j}$, respectively. //

We have therefore shown that the maximally informative equilibrium under international auditing has weakly richer information than that of central bank auditing for all $\beta$, and has strictly richer information for some set of $\beta$. We conclude the proof.

\section{References}

[1] Blejer, M., E. Feldman, and A. Feltenstein (2002), "Exogenous Shocks, Contagion, and Bank Soundness: A Macroeconomic Framework," Journal of International Money and Finance, 21: pp. 33-52.

[2] Crawford, V. and J. Sobel (1982), "Strategic Information Transmission," Econometrica, 50:1431-51.

[3] Diamond, D. and P. Dybvig (1983), "Bank Runs, Deposit Insurance, and Liquidity," Journal of Political Economy, 91(3), pp. 401-419.

[4] Diamond, D. and R. Rajan (2001), "Liquidity Risk, Liquidity Creation, and Financial Fragility: A Theory of Banking," Journal of Political Economy, Vol 109, April, pp. 287-327. 
[5] Eaton, J. (2002), "Standstills and an International Bankruptcy Court," unpublished manuscript.

[6] Fudenberg, D. and J. Tirole (1991), Game Theory, Cambridge: MIT Press.

[7] Kletzer, K. (1984), "Asymmetries of Information and LDC Borrowing with Sovereign Risk," Economic Journal, 94: 287-307.

[8] Kletzer, K. and B. Wright (1999), "Sovereign Debt as Intertemporal Barter," American Economic Review, 90: 621-39.

[9] Krishna, V. and J. Morgan (1999), "A Model of Expertise," Quarterly Journal of Economics, 116: 747-75.

[10] Krueger, A. O. (2001), "International Financial Architecture for 2002: A New Approach to Sovereign Debt Restructuring," address given at the National Economists Club Annual Members Dinner, American Enterprise Institute, Washington, DC.

[11] Laffont, J-J. and D. Martimort (1999), "Separation of Regulators against Collusive Behavior," Rand Journal of Economics, 30: 232-62.

[12] Lagunoff, R. (2002), "Credible Communication in Dynastic Government ," unpublished, Georgetown University, revised, April, 2003.

[13] Maskin, E. and J. Tirole (2001), "The Politician and the Judge: Accountability in Government," unpublished, April.

[14] Morris, S. and H. S. Shin (2003), "Catalytic Finance: When Does it Work?" Cowles Foundation Discussion Paper No. 1400, February.

[15] Peck, J. and K. Shell (2003), "Equilibrium Bank Runs," Journal of Political Economy, 111: February, pp. 103-123.

[16] Persson, T. G. Roland, and G. Tabellini (1997), "Separation of Powers and Political Accountability," Quarterly Journal of Economics, 112:1163-1202.

[17] Rogoff, K. and J. Zettelmeyer (2002), "Bankruptcy Procedures for Sovereigns: A Brief History of Ideas, 1976-2001," IMF Working Paper 02/133. 